\title{
The Effect of Sizes of the Cast Polyamide 6 Rods upon Tensile-Impact Strength
}

\author{
M. ODROBINA, G. KALÁCSKA, R. Zs. KERESZTES
}

Szent István University, Institute for Mechanical Engineering Technology, odrobina.miklos@hallgato.szie.hu Szent István University, Institute for Mechanical Engineering Technology, kalacska.gabor@gek.szie.hu Szent István University, Institute for Mechanical Engineering Technology, keresztes.robert@gek.szie.hu

\begin{abstract}
We have studied the tensile-impact strength of the magnesium catalysed cast polyamide 6 (PA6) rods according to the EN ISO 8256:2004 standard. The purpose of our investigation was to follow: the mechanical properties of rods are mapped beside same casting technological process in case of different diameters. We have compared the received results with each other than have sought disparities. We examined cylindrical product (rod) in seven dimensional steps in diameter ranging from $40 \mathrm{~mm}$ to $300 \mathrm{~mm}$. We have determined that the semi-finished products can be divided into two groups typically in case of their tensile-impact strengths in this size range. The tensile-impact strength is higher in case of the rods with a diameter of less than $100 \mathrm{~mm}$ and it is smaller in the larger dimension range. Therefore, the smallest tensile-impact strength can be established in case of the natural semifinished PA6 rods that each rod accomplishes independently of size. However, a range can be determined, which the tensile-impact strength values of product are separated according to the manufacturing size.
\end{abstract}

Keywords: cast polyamide 6, tensile-impact test, semi-finished product, plastic, PA6

\section{Introduction}

Plastics are being used now not only in secondary locations, such as packaging materials, but also as load-bearing machine element due to the increasing supply of plastic industry. One of the most commonly used technical polymers is the polyamide (PA), and he most commonly used type of its family is polyamide 6 (PA6). It has good tribological, for instance, abrasion resistance, sliding and gliding, and mechanical, for example, hardness, toughness, strength, properties. In addition, lubricant filled and/or fibre reinforced base materials are available to ensure special properties (better wear resistance and sliding, greater dimensional stability and strength) [2]. The properties of semi-finished products in case of PA6 depend on the production technology and the input material extraordinarily. The polyamides can also be applied in mass production, such as extrusion and casting [4]. Both engineering experience and laboratory measurements have shown that the mechanical properties of extruded and cast polyamide 6 rods are slightly different. 

In earlier research work in Hungary, the industrial manufacturing technology of cast PA6 with magnesium catalysis was developed in case of semi-finished products. The advantage of this technology is that it has a more homogeneous structure than previously known sodium catalysed PA6 products, has a less residual monomer content and higher degree of crystallinity. Its improved toughness (without additives) and constant material structure stands out from the cast polyamide products due to the specially catalysed manufacturing process. In comparison with extruded, pure PA 6 materials, it has greater strength, dimensional stability and wear resistance. It has both the favourable properties of extruded and cast polyamides. It is a universally usable structural material (gear wheels, bearings, rollers) which is economically more favourable in comparison with other polyamide products.

The fundamental question is to follow: How do the particularities of the polymer manufacturing technology affect the resulting mechanical properties? In this examination we have studied the tensileimpact strength value of magnesium catalysed cast PA 6 rods. We look for the differences in aforementioned parameters in case of seven different diameters of magnesium catalysed cast polyamide 6 semi-finished products.

\section{METHODS}

Tensile Impact Test (ISO 8256/ASTM D 1822). The tensile impact strength test was developed to overcome the deficiencies of flexural impact tests, for instance, Charpy or Izod. The test variables, such as toss factor, notch sensitivity and specimen thickness, are eliminated in the tensile impact test. This test allows the user to determine the impact strength of flexible and very thin specimens. Many other characteristics of polymers, such as the orientation effect and the anisotropy, can be studied through the use the aforementioned test $[5,6]$.

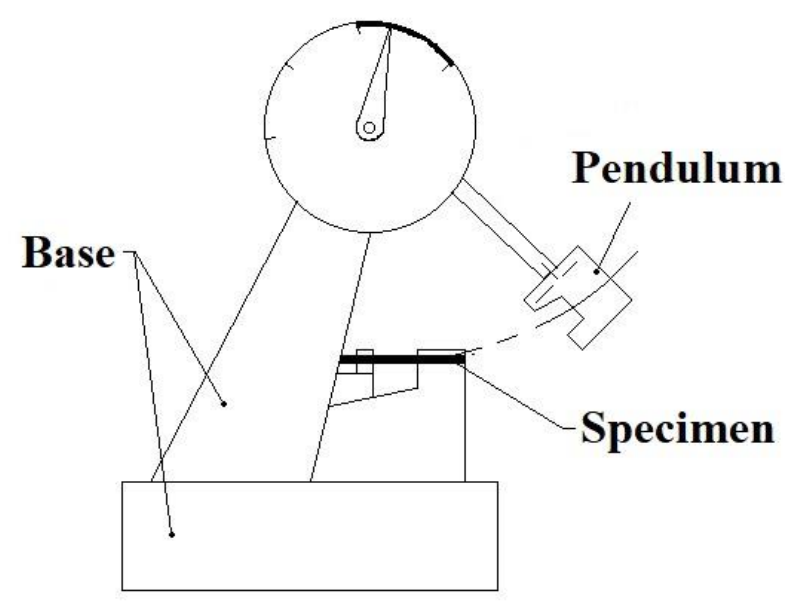

Figure 1. Parts of Tensile Impact Machine

The notched or non-notched specimen is located horizontally. It is clamped by the jaw of anvil and the crosshead. The orientation of the specimen is the same as that the way of pendulum movement. In this test method the energy utilized is delivered by a single swing of a calibrated pendulum of a standardized tension-impact machine (Figure 1). The specimen is hit at the lowest point of the swing by the pendulum. The energy to fracture by shock in tension is determined by the kinetic energy extracted from the pendulum of a tensile-impact machine in the process of breaking the specimen [1]. The standard specifies two methods (method A and method B) for the determination of the tensile-impact strength of plastics under defined conditions [3]. 
The crosshead may be mounted either stably on the anvil (method A) or movable with the pendulum (method B). We used the method A. The dimensions of specimen is illustrated by Figure 2 [3].

Further, this is still a uniaxial examination and most impact events are multiaxial in real-life situations.

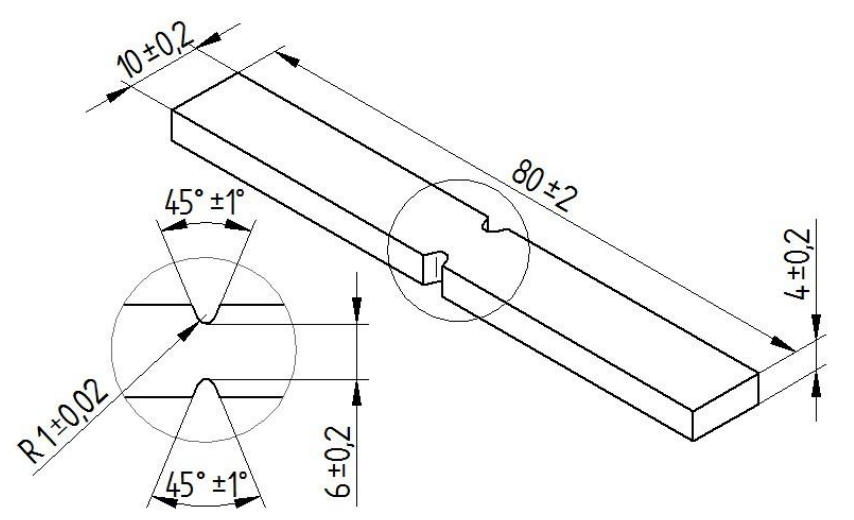

Figure 2. MSZ ISO 8256/1B type specimen

\section{RESULTS}

In the literature, there is little information for the polymers to break the tensile-impact strength. This measurement method is less widespread. Charpy and Izod impact tests are used in case of dynamic strength testing. The tensile-impact test is performed on materials that are difficult or not at all to break. It is worth studying the trends, averages and deviations that can be determined from the obtained values.

Based on the results of the tensile-impact tests, the values of tensile-impact strength fluctuate between $89 \mathrm{~kJ} / \mathrm{m} 2$ and $106 \mathrm{~kJ} / \mathrm{m} 2$, the average is $\bar{x}=98,94 \mathrm{~kJ} / \mathrm{m}^{2}$ and it is typical of the whole series of test that the coefficient of variation is around $12 \%$, which is very good in the case of dynamic tests. It suggests a homogeneous structure of the PA6.

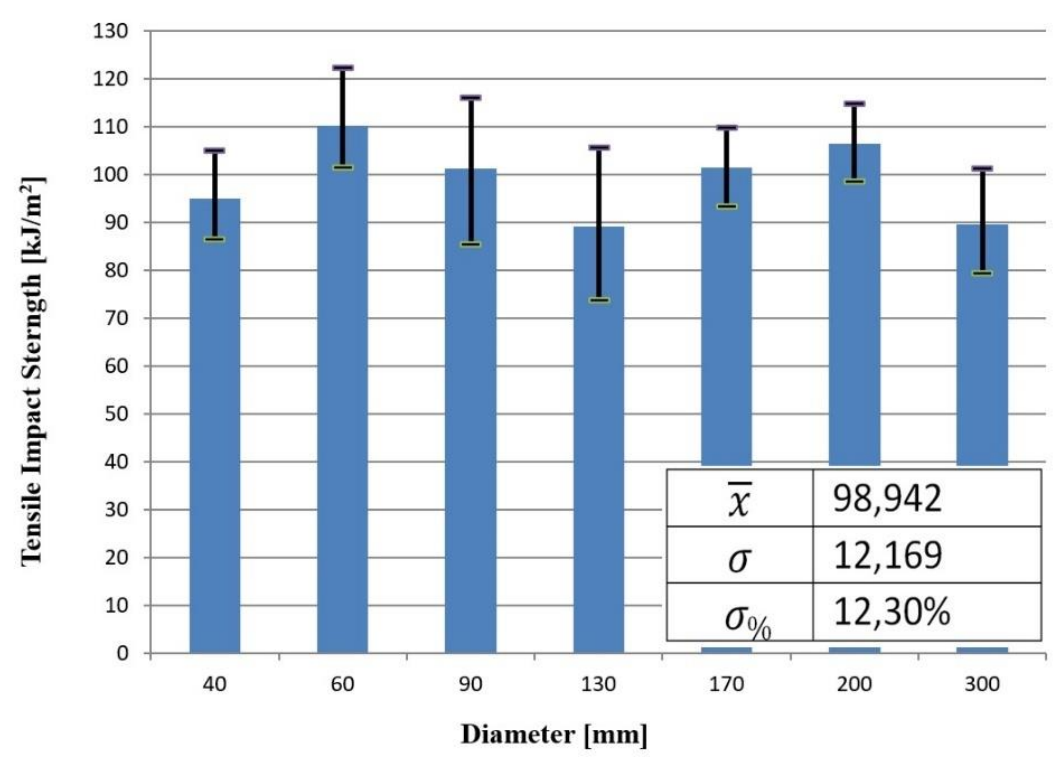

Figure 3. Results of Tensile Impact Test

There is an interesting trend (Figure 3). The rod with 40, 60, 90 and 170 and $200 \mathrm{~mm}$ diameter has an almost identical tensile-impact strength. The tensile-impact strengths of rods with 130 and $300 \mathrm{~mm}$ diameter are lower. 
I have determined the following from the received results:

The PA6 rods can be classified in 2 categories based on the impact strength values:

Category 1: Rods with 40, 60, 90 and 170 and $200 \mathrm{~mm}$ diameter, they have the best tensile-impact strength.

Category 2: Rods with 130 and $300 \mathrm{~mm}$ diameter, they have reduced tensile-impact strength, but these are also favorable.

\section{CONCLUSIONS}

Based on the axial orientation specimens taken from the centre of the rods with seven different diameters, it can be established that the tensile-impact strength is not constant in case of the natural cast PA6 rods that produced with a particular manufacturing technology.

In the 40 to $300 \mathrm{~mm}$ dimension range of magnesium catalysed PA6 (DOCAMID 6G-H), the tensile-impact strength is in the range of 86 to $106 \mathrm{~kJ} / \mathrm{m} 2$.

The reason of the deviation of the tensile-impact strengths is found in the production technology. These materials are formed theoretically in adiabatic polymerization, the less true is that the system is adiabatic in case of rod with smaller diameter. The warming of the rods under the polymerization process, the thermal equilibrium of system depends on many external conditions. One of the most important is the actual diameter, for example, there is very little difference between the outside and the inside of the rod with $50 \mathrm{~mm}$ diameter.

Ultimately, the thermal dynamics of the technology will determine the mechanical properties of the product, including the tensile-impact strength.

\section{References}

[1] ASTM D1822-13, Standard Test Method for Tensile-Impact Energy to Break Plastics and Electrical Insulating Materials.

[2] G. Erhard, Designing with Plastics, Hanser Publishers, Munich, 2006.

[3] MSZ EN ISO 8256:2004(E) standard, Plastics -Determination of tensile-impact strength.

[4] O. Olabisi, K. Adewale, Handbook of Thermoplastics, Second Edition, CRC Press, Boca Raton, 2016.

[5] L. Pék, L. Pellényi, I. Pálinkás, Anyagszerkezettan és anyagismeret, Budapest: Dinasztia Publisher, 2000.

[6] V. Snah, Handbook of Plastics Testing and Failure Analysis, Third Edition. John Wiley \& Sons, Inc., Hoboken, New Jersey, 2007. 